\title{
Evolução da qualidade microbiológica de queijo Minas frescal comercializado em Curitiba (PR) no intervalo de 10 anos (1999 e 2009)
}

\author{
Assessment of the microbiological quality of Minas frescal \\ cheese commercialized in the city of Curitiba, Parana \\ State, Brazil at 10 years' interval (1999 and 2009)
}

Hanna Lethycia Wolupeck $k^{[a]}$, Helen Caroline Raksa ${ }^{[a]}$, Luciane Silvia Rossa ${ }^{[b]}$, Raquel Biasi[ ${ }^{[b]}$, Renata Ernlund Freitas de Macedo ${ }^{[c]}$

[a] Médica-veterinária, mestranda em Ciência Animal, Escola de Ciências Agrárias e Medicina Veterinária, Pontifícia Universidade Católica do Paraná (PUCPR), São José dos Pinhais, PR - Brasil, e-mail: lethyciawolupeck@yahoo.com.br, helen.raksa@hotmail.com

[b] Médica-veterinária, mestre em Ciência Animal, Escola de Ciências Agrárias e Medicina Veterinária, Pontifícia Universidade Católica do Paraná (PUCPR), São José dos Pinhais, PR - Brasil, e-mail: lu.rossa@hotmail.com, quel_biasi@yahoo.com.br

[c] Médica-veterinária, doutora em Tecnologia de Alimentos, professora do curso de Mestrado em Ciência Animal, Escola de Ciências Agrárias e Medicina Veterinária, Pontifícia Universidade Católica do Paraná (PUCPR), São José dos Pinhais, PR - Brasil, e-mail: renata.macedo@pucpr.br

\section{Resumo}

O queijo Minas frescal é um dos mais populares do Brasil, porém o alto teor de umidade associado ao método de processamento, muitas vezes artesanal, e de armazenamento desse produto o tornam muito perecível. Este trabalho teve como objetivo avaliar e comparar a qualidade microbiológica de queijo Minas frescal comercializado na cidade de Curitiba (PR) nos anos de 1999 e 2009, verificando a evolução na qualidade higiênico-sanitária desse produto no período de 10 anos. Foram analisadas 11 marcas comerciais de queijo Minas frescal disponíveis no comércio varejista da cidade de Curitiba, sendo amostradas cinco unidades de cada marca, totalizando 55 amostras. Os queijos foram submetidos à pesquisa de Salmonella spp., contagem de coliformes totais e Escherichia coli, contagem de Staphylococcus coagulase positiva e contagem de aeróbios mesófilos, com resultados expressos em UFC/g. Das 55 amostras de queijo, 41,82\% e 78,18\% apresentaram contagem de $E$. coli e de coliformes totais acima do limite permitido, respectivamente. Somente uma amostra $(1,82 \%)$ do total avaliado mostrou-se em desacordo com os padrões para $S$. coagulase positiva e uma para Salmonella spp. Ambas as amostras foram adquiridas em 2009. Todas as amostras avaliadas em 2009 apresentaram elevada contagem de aeróbios mesófilos, revelando alta carga microbiana. Comparativamente, os queijos avaliados em 1999 mostraram qualidade microbiológica superior aos queijos avaliados em 2009 (p < 0,05). Destes, 100\% apresentaram no mínimo um parâmetro microbiológico em desacordo com a legislação vigente, indicando que a qualidade dos queijos Minas frescal avaliados em 2009 apresentou-se inferior a dos queijos avaliados em 1999.

Palavras-chave: Queijo Minas. Inocuidade. Saúde pública. 


\section{Abstract}

Minas cheese is one of the most popular Brazilian cheeses, however its high moisture content, processing method, often handmade, and storage conditions are determinants for its short shelf-life. This study aimed to evaluate and compare the microbiological quality of Minas frescal cheese commercialized in the city of Curitiba, Parana State, Brazil, in 1999 and 2009, in order to assess the progress in the sanitary quality of this product during a period of 10 years. Five units of Minas cheese from 11 commercial brands available in retail stores in the city of Curitiba were assessed, giving a total of 55 samples. Samples were analyzed for total coliforms, Escherichia coli, coagulase positive Staphylococcus, aerobic mesophilic bacteria and Salmonella sp. Results were expressed as CFU/g. From the 55 cheese samples, $41.82 \%$ and $78.18 \%$ showed count of Escherichia coli and total coliform above the legislation standards, respectively. One sample (1.82\%) showed number of coagulase positive Staphylococcus above the acceptable limit established by the Brazilian regulation and one sample showed presence of Salmonella spp. Both samples were evaluated in 2009. Furthermore, all the samples tested in 2009 showed high counts of aerobic mesophilic bacteria, revealing great microbial load. Comparatively, Minas cheeses analyzed in 1999 showed higher microbiological quality than cheeses evaluated in $2009(P<0.05)$. All cheese samples from 2009 presented at least one of the microbiological parameters in discordance with the Brazilian regulation, indicating that the quality of Minas frescal cheese evaluated in 2009 was lower than in cheese evaluated in 1999.

Keywords: Fresh cheese. Safety. Public health.

\section{Introdução}

Há muitos anos, o queijo é um alimento de relevância na dieta de grande parte da população mundial (PEREIRA; GOMES; MALCATA, 2009), e o Brasil é o quinto maior produtor mundial de leite, cujo principal destino é a fabricação de queijos, para a qual é encaminhada aproximadamente 34\% da produção leiteira (EMPRESA BRASILEIRA DE PESQUISA AGROPECUÁRIA - EMBRAPA, 2010).

Segundo pesquisa realizada pelo Sebrae (2008), o percentual de domicílios que adquiriu algum produto da categoria dos queijos nos lares brasileiros em 2003 foi de $68 \%$.

No Brasil, são fabricados mais de 70 tipos de queijos, o queijo tipo mussarela é o mais produzido (cerca de $29 \%$ do mercado), seguido do queijo prato, com aproximadamente $20 \%$ e do queijo Minas frescal com $6 \%$ da produção nacional (SEBRAE, 2008). Os queijos são diferenciados pelo método de processamento, teor de gordura e umidade; e adição de ingredientes, como cultivos de bactérias lácticas, condimentos, ou outros ingredientes opcionais (BRASIL, 1996).

Ainda que o queijo Minas frescal esteja na terceira posição entre os queijos produzidos no Brasil, ele é consumido por todas as camadas da população e durante todo o ano. Acredita-se que tenha sido o primeiro tipo de queijo fabricado no país. É uma variedade não maturada, para consumo imediato e de curto tempo de prateleira, de apenas 21 dias em embalagem fechada e sob refrigeração, devendo ser consumido em até cinco dias após a abertura da embalagem. Graças ao seu baixo teor em lipídeos é bastante associado a dietas com restrição de gorduras (FURTADO, 1999; SEBRAE, 2008).

Segundo a legislação brasileira, a variedade Minas frescal é definida como um queijo fresco obtido por coagulação enzimática do leite com coalho e/ou outras enzimas coagulantes apropriadas, complementada ou não pela ação de bactérias lácticas específicas (BRASIL, 1997; 2004).

O queijo Minas frescal caracteriza-se como um queijo semigordo, com $25,0 \%$ a $44,9 \%$ de gordura, de elevada umidade (não inferior a 55,0 \%), pH (com fermento) entre 5,0 e 5,3 ou pH (acidificado com ácido lático) de 6,1 a 6,3 e porcentagem de sal de 1,4\% a 1,6\% (BRASIL, 1996; FURTADO, 1999).

Por causa da tecnologia simples de processamento do queijo Minas frescal, a produção é em sua maioria representada por pequenos e médios produtores, muitos deles artesanais (BEHMER, 1999; 
SOUZA et al., 2008). Apesar de a legislação brasileira estabelecer a utilização de leite pasteurizado no seu preparo (BRASIL, 1997), é frequente a comercialização informal de queijo Minas frescal produzido com leite cru, graças à crença de que o uso desse tipo de leite torna o queijo mais aromático e saboroso (PEREIRA et al., 1991). Por isso, a qualidade do queijo Minas frescal produzido no país é bastante irregular, tendo, na maioria de seus métodos de processamento, intensa manipulação, que, somado ao alto teor de umidade do produto, o torna muito perecível (FURTADO; LOURENÇO NETO, 1994).

Além disso, a comercialização desse tipo de queijo também ocorre em mercados abertos, sem as condições adequadas de refrigeração ou proteção contra contaminantes físicos e biológicos (INMETRO, 1999; LEITE et al., 2001; SOUZA et al., 2008).

As condições de produção, distribuição e comercialização podem, além de comprometer as características sensoriais do queijo, torná-lo impróprio para o consumo em virtude da contaminação por micro-organismos deteriorantes e patogênicos. A ação microbiana altera a qualidade sensorial do queijo por causa da atividade enzimática proteolítica e/ou lipolítica de fungos e leveduras, coliformes e outros micro-organismos sobre os componentes do queijo, promovendo modificações químicas que interferem nas características sensoriais do produto (FRANK et al., 2005; PERRY, 2004; WOLFSCHOONPOMBO, 1983). Além disso, a contaminação por patógenos assume importância tanto para a indústria pelas perdas econômicas, como para a saúde pública pelo risco da transmissão de enfermidades pelo consumo de queijo (FEITOSA et al., 2003).

As doenças transmitidas por alimentos (DTAs) são um problema crescente de saúde pública mundial, visto que a contaminação pode ocorrer em qualquer fase do processo de produção. A forma clínica mais comumente observada das DTAs são os sintomas gastrintestinais (WHO, 2012a).

Em virtude do consumo e da popularidade do queijo Minas frescal no mercado consumidor brasileiro e das condições de processamento e comercialização praticadas no país desse tipo de queijo, o presente trabalho teve como objetivo a avaliação da qualidade microbiológica de queijo Minas frescal comercializado na cidade de Curitiba (PR) nos anos de 1999 e 2009.

\section{Materiais e métodos}

0 estudo foi realizado em duas etapas: a primeira em 1999 e a segunda em 2009. No total foram analisadas 55 amostras de queijo Minas frescal, de 11 diferentes marcas comerciais, adquiridas no comércio varejista da cidade de Curitiba (PR), mas produzidas em diferentes estados do país e contendo selo dos Serviços de Inspeção Federal ou Estadual. Em 1999, foram analisadas 25 amostras de cinco diferentes marcas comerciais (denominadas de A1 a E1) e em 2009 foram analisadas 30 amostras de seis diferentes marcas (denominadas de A2 a F), os dois períodos avaliados, foram coletadas cinco unidades amostrais de cada marca.

Nos locais de comercialização, durante a coleta, as amostras foram acondicionadas em recipiente contendo gelo para preservação das condições de refrigeração e imediatamente transportadas ao laboratório para a análise microbiológica, que foi realizada em um período de no máximo duas horas após a coleta.

A análise microbiológica foi realizada pela pesquisa de Salmonella spp., contagem de coliformes totais e de E. coli, contagem de $S$. coagulase positiva e contagem de aeróbios mesófilos, sendo esta última determinação realizada apenas nas amostras coletadas em 2009. Todas as determinações foram realizadas em duplicata, procedendo-se a coleta asséptica de $25 \mathrm{~g}$ de cada amostra que foram homogeneizadas em $225 \mathrm{~mL}$ de água peptonada estéril 0,1\% (Himedia, RM001, Mumbai - Índia) com o auxílio de homogeneizador (Stomacher 400 Circulador) a $230 \mathrm{rpm} / 1$ minuto. Posteriormente, para as contagens, procedeu-se a diluição seriada de $1 \mathrm{~mL}$ das amostras em $9 \mathrm{~mL}$ de água peptonada estéril $0,1 \%$, seguida de semeadura em placas para as contagens microbiológicas.

Acontagem total de aeróbios mesófilosfoi realizada em ágar PCA (Plate Count Agar - HIMEDIA, M091, Mumbai - Índia) com incubação a $37{ }^{\circ} \mathrm{C} / 48$ horas. As contagens de coliformes totais e de E. Coli foram realizadas em placas Petrifilm EC (3M, St Paul-USA) com incubação a $37{ }^{\circ} \mathrm{C} / 48$ horas e a contagem de S. coagulase positiva foi realizada em ágar Baird Parker (Acumedia, Neogen Corporation Lansing Michigan) suplementado com gema de ovo e telurito de sódio (NEWPROV, Pinhais, PR-Brasil), incubado a $35^{\circ} \mathrm{C} / 48$ horas e confirmação pelas provas de Gram, coagulase e catalase. Os resultados das 
contagens foram expressos em unidades formadoras de colônia (UFC)/g de amostra.

Paraa pesquisa de Salmonella spp., foi utilizadaágua peptonada estéril 1\% (Himedia, RM001, Mumbai Índia), como pré-enriquecimento, incubada a $35^{\circ} \mathrm{C} /$ 24 horas. 0 enriquecimento foi realizado nos caldos Selenito-Cistina (Selenite Cystine Broth - DIFCOTM, Le Pont de Claix - France) e Tetrationato-Novobiocina de Mueller Kauffmann (Muller-Kauffmann Tetrathionat Novobiocin - MERCK, Darmstadt - Germany), com incubação a $35^{\circ} \mathrm{C} / 24$ horas. Após a incubação, foi realizado estriamento dos caldos de enriquecimento e pré-enriquecimento nos meios seletivos ágar SS (SalmonellaShighella - HIMEDIA, Mumbai - Índia) e ágar XLD (Agar Xilose Lisina Desoxicolato, HIMEDIA, Mumbai - Índia). Tubos contendo meio Rugai com Lisina (NEWPROV, Pinhais, PR - Brasil) foram utilizados para identificação bioquímica presuntiva de Salmonella spp. e a confirmação foi realizada por sorologia (Soro Salmonella polivalente, PROBAC, São Paulo, SP - Brasil) (BRASIL, 1992, 2003; SILVA et al., 2007).

A análise dos resultados foi realizada pelos cálculos de média e porcentagem e por análise de variância (ANOVA) para verificação de diferenças significativas dos resultados obtidos entre as marcas dentro de cada período avaliado, adotando-se nível de significância de 5\%. Quando detectadas diferenças significativas entre as marcas, o teste de Tukey foi empregado para a comparação das médias. As médias obtidas nas contagens microbianas dos queijos nos anos 1999 e 2009 foram comparadas pelo teste t com probabilidade de $5 \%$.

\section{Resultados e discussão}

A qualidade microbiológica dos queijos no Brasil é regulamentada pela Agência Nacional de Vigilância Sanitária (Anvisa), mediante a RDC 12 de 2001, que estabelece os Padrões Microbiológicos para Alimentos (BRASIL, 2001), e pelo Ministério da Agricultura, Pecuária e do Abastecimento (Mapa) mediante a Portaria 146 de 1996 que fixa os requisitos microbiológicos para queijos (BRASIL, 1996). Ambas as legislações devem ser obedecidas para a garantia da inocuidade dos queijos desde a etapa de processamento até sua distribuição final.

Os coliformes totais são bactérias da família Enterobacteriaceae dos quais fazem parte os gêneros Escherichia, Klebsiella, Enterobacter e Citrobacter.
O grupo coliforme fecal foi originalmente definido como os coliformes totais que apresentavam a capacidade de continuar fermentando a lactose com produção de gás a temperatura de 44 a $45^{\circ} \mathrm{C}$. Nesse grupo deveriam estar somente espécies de origem fecal exclusiva, como a E. coli, porém, levando-se em consideração o crescimento na referida faixa de temperatura para a classificação neste grupo, algumas cepas de Enterobacter e Klebsiella também podem estar incluídas (SILVA et al, 2010). Diferentemente dos demais coliformes dos gêneros Enterobacter, Citrobacter e Klebsiella, que podem estar presentes em outros ambientes como o solo, a E. coli é encontrada somente no trato intestinal do homem e animais de sangue quente. Por isso, a determinação específica de E. coli nos alimentos como indicador de poluição fecal é mais recomendada do que a determinação de coliformes fecais (MOSSEL; MORENO, 1988; SILVA et al., 2010).

Por ser facilmente destruída por tratamentos térmicos como a pasteurização, em queijos a E. coli é usada como indicador de problemas na pasteurização do leite, seja por condições de subpasteurização ou contaminação pós-pasteurização. A legislação brasileira vigente especifica que o leite pasteurizado deve apresentar número de coliformes fecais inferior a $2 \mathrm{NMP} / \mathrm{mL}$ (BRASIL, 2011). Além disso, sua presença também indica problemas no processamento do queijo, por más condições higiênicas durante o processamento ou contaminação após o processamento (O'BRIEN et al., 2009).

Adicionalmente, a presença de E. coli nos alimentos é preocupante do ponto de vista sanitário em virtude da existência de sorotipos altamente patogênicos aos humanos e de ocorrência recente em surtos alimentares. Em 2011 um surto alimentar ocasionado por Shiga-like, toxina produzida por E. coli sorotipo 0104:H4, resultou na morte de 34 pessoas graças à Síndrome Urêmico Hemolítica na Alemanha (WHO, 2012b).

O limite máximo estabelecido para queijos de muito alta umidade (umidade $>55 \%$ ), sem adição de bactérias lácticas, pelo Mapa (BRASIL, 1996) e pela Anvisa (BRASIL, 2001) para coliformes a $45^{\circ} \mathrm{C}$ ou coliformes fecais é de 5,0 × $102 \mathrm{UFC} / \mathrm{g}$.

Das 25 amostras de queijo frescal avaliadas em 1999, 32\% (8) estavam em desacordo com a legislação vigente para E. coli (BRASIL, 1996; BRASIL, 2001). No entanto, em 2009, maior porcentagem de amostras de queijo Minas (50\%) mostrou-se em 
desacordo com a legislação para este micro-organismo de origem fecal.

Considerando a contagem de E. coli por marca de queijo avaliado (11 marcas), os valores variaram de 1 x 102 a 8,2 x 105 UFC/g (Tabela 1), sendo que as contagens médias nas amostras nos anos de 1999 (1,2 x 103 UFC/g) e 2009 (1,7 x 105 UFC/g) superaram o limite permitido na ordem de $0,3 \mathrm{e}$ 2,5 log, respectivamente.

Entre as 55 amostras, $23(41,82 \%)$ apresentaram contagens de E. coli acima do limite permitido, com valores que variaram de 7,0 x 102 a 2,1 x $106 \mathrm{UFC} / \mathrm{g}$. Apesar da porcentagem relevante de amostras de queijo Minas acima do permitido para E. coli, Salotti et al. (2006) verificaram valor ainda maior $(66,7 \%)$ em amostras de queijo Minas frescal comercializadas em Jaboticabal (SP). Isepon et al. (2003) também relataram alta porcentagem (70\%) de amostras de queijo frescal avaliados em Ilha Solteira (SP) em desacordo com a legislação.

$\mathrm{Na}$ avaliação comparativa da contagem média de E. coli entre as amostras avaliadas em 1999 e em 2009 verificou-se diferença significativa $(\mathrm{p}<0,05)$ entre os valores, sendo a contagem de E. coli nas amostras em 2009 foi superior à contagem em 1999 (Tabela 1).
A contagem de coliformes totais nos queijos é indicativa de sua qualidade higiênico-sanitária (SIQUEIRA, 1995). A determinação de coliformes totais é exigida pelo Mapa para queijos de muito alta umidade (> 55\%), que estabelece número máximo de 1 x 103 UFC/g (BRASIL, 1996). Das 55 amostras analisadas, 78,18\% (43) apresentaram número de coliformes totais acima do limite, com valores que variaram de 2 x 103 a 3,4 x 109 UFC/g. 0 resultado indica condições higiênicas precárias durante a manipulação e processamento dos queijos e/ou tratamento térmico insuficiente da matéria-prima (SILVA et al., 2010). Araújo et al. (2001) pesquisaram o nível de contaminação por coliformes totais em queijos Minas comercializados em Salvador, BA e verificaram contaminação acima do limite permitido em $75 \%$ das amostras.

Na avaliação por ano, 52\% das amostras em 1999 estavam em desacordo com a legislação vigente para coliformes totais, ao passo que em 2009, $100 \%$ das amostras apresentaram contaminação por coliformes totais acima do limite. A contagem média de coliformes nas amostras avaliadas em 2009 (1,7 x 105 UFC/g) também se mostrou superior $(p>0,05)$ à contagem média observada nas amostras em 1999 (1,2 x 103 UFC/g).

Tabela 1 - Contagem média de aeróbios mesófilos nas marcas comerciais de queijo tipo Minas frescal avaliadas em 2009 e contagens médias comparativas de coliformes totais e Escherichia coli entre as marcas avaliadas nos anos de 1999 e 2009 na cidade de Curitiba (PR)

\begin{tabular}{|c|c|c|c|c|c|c|}
\hline \multicolumn{2}{|c|}{ Marcas } & \multicolumn{2}{|c|}{$\begin{array}{l}\text { Coliformes totais } \\
\text { (UFC/g) }\end{array}$} & \multicolumn{2}{|c|}{$\begin{array}{l}\text { Escherichia coli } \\
\text { (UFC/g) }\end{array}$} & \multirow{2}{*}{$\begin{array}{c}\text { Mesófilos } \\
\text { (UFC/g) }\end{array}$} \\
\hline 1999 & 2009 & 1999 & 2009 & 1999 & 2009 & \\
\hline A1 & $A 2$ & $<10^{2 b}$ & $1,0 \times 10^{5 a}$ & $<10^{2 b}$ & $1,0 \times 10^{5 a}$ & $3,1 \times 10^{7 b}$ \\
\hline B1 & B2 & $9,9 \times 10^{5 a}$ & $6,0 \times 10^{8 a}$ & $4,6 \times 10^{3 a}$ & $8,8 \times 10^{2 b}$ & $5,0 \times 10^{7 b}$ \\
\hline $\mathrm{C} 1$ & $\mathrm{C} 2$ & $5,1 \times 10^{5 a}$ & $9,6 \times 10^{8 \mathrm{ab}}$ & $9,6 \times 10^{2 a b}$ & $2,8 \times 10^{2 \mathrm{~b}}$ & $5,0 \times 10^{7 b}$ \\
\hline D1 & D2 & $1,1 \times 10^{7 \mathrm{a}}$ & $5,0 \times 10^{8 b}$ & $<10^{2 b}$ & $<10^{2 b}$ & $5,0 \times 10^{7 b}$ \\
\hline \multirow[t]{2}{*}{ E1 } & E2 & $<10^{2 b}$ & $2,9 \times 10^{7 \mathrm{ab}}$ & $<10^{2 b}$ & $8,2 \times 10^{5 a}$ & $5,0 \times 10^{7 b}$ \\
\hline & $\mathrm{F}^{*}$ & - & $1,1 \times 10^{5 a}$ & - & $1,1 \times 10^{5 a}$ & $1,1 \times 10^{9 \mathrm{a}}$ \\
\hline \multicolumn{2}{|c|}{ Média } & $2,5 \times 10^{6 B}$ & $3,4 \times 10^{8 \mathrm{~A}}$ & $1,2 \times 10^{3 B}$ & $1,7 \times 10^{5 \mathrm{~A}}$ & $2,3 \times 10^{8}$ \\
\hline \multicolumn{2}{|c|}{ Valores limite** } & \multicolumn{2}{|c|}{$1 \times 10^{3}$} & \multicolumn{2}{|c|}{$5,0 \times 10^{2}$} & $1 \times 10^{6}$ \\
\hline
\end{tabular}

Fonte: Dados da pesquisa.

Nota: * Marca F avaliada somente no ano 2009; letras minúsculas diferentes na mesma coluna indicam diferença significativa em nível de $5 \%$ entre as marcas avaliadas no mesmo ano; letras maiúsculas diferentes na mesma linha para o mesmo tipo de micro-organismo indicam diferença significativa em nível de 5\% entre os anos 1999 e 2009; ** valores de referência estabelecidos pelo Ministério da Agricultura, Pecuária e do Abastecimento (BRASIL, 1996), Anvisa (BRASIL, 2001) e Código Sanitário (SÃO PAULO, 1992). 
A contagem de coliformes totais variou significativamente entre as marcas de queijo tanto em 1999 quanto em 2009 ( $\mathrm{p}<0.05)$. Em 1999, os valores variaram de < 102 a $1,1 \times 107 \mathrm{UFC} / \mathrm{g}$, enquanto que em 2009, a média mínima foi de 1,0 x 105 UFC/g e a máxima de 9,6 x 108 UFC/g.

Bactérias patogênicas como Salmonella spp., $S$. aureus, Listeria monocytogenes e E. coli são consideradas as principais ameaças para a inocuidade dos queijos (DE BUYSER et al., 2001).

A L. monocytogenes é destruída nos processos de pasteurização e cozimento. Portanto, os queijos frescos, de massa macia e os de curta maturação, são considerados os de maior risco de contaminação por esse micro-organismo (RUDOL; SCHERER 2001). E apesar de ter sido isolada em diversos tipos de alimento, como leite cru, peixes, carnes e alimentos prontos para consumo, o relato da ocorrência de L. monocytogenes em alimentos é recente (O'BRIEN et al., 2009). Dessa forma, quando a primeira etapa deste estudo foi realizada em 1999, a pesquisa de L. monocytogenes em queijos não era exigida pela legislação brasileira e, por isso, as amostras de queijo coletadas naquele ano não foram avaliadas para esse patógeno. A exigência passou a vigorar em 2001, com a RDC n. 12 da Anvisa, que considera como padrão a ausência do patógeno em $25 \mathrm{~g}$ do produto (BRASIL, 2001). Neste sentido, pela falta de resultados iniciais para a comparação da presença de L. monocytogenes em queijos no intervalo de 10 anos, optou-se por não realizar a determinação nas amostras em 2009.

Contudo, como forma de avaliar o grau de contaminação microbiana e obter indícios da potencial presença de patógenos mesófilos nos queijos, entre os quais L. monocytogenes, realizou-se a contagem de aeróbios mesófilos nas amostras em 2009.

A legislação brasileira federal não estabelece limite para esse grupo de microrganismo indicador em alimentos. No entanto, a legislação sanitária do Estado de São Paulo considera o valor de 1 x 106 UFC/g como limite para a contagem de aeróbios mesófilos em produtos alimentícios manipulados (SÃO PAULO, 1992).

Considerando esse grupo de micro-organismos, todas as amostras avaliadas em 2009 mostraram contagens acima do limite, revelando elevada carga microbiana, a qual pode refletir na curta vida de prateleira do produto. As contagens de aeróbios mesófilos nas marcas de queijo variaram de 3,1 x
107 a 1,1 x 109 UFC/g, com valor médio de 2,3 x 108 UFC/g (Tabela 1). A contaminação por aeróbios mesófilos indica deficiências no processamento, armazenamento e/ou distribuição dos queijos.

As bactérias do gênero Salmonella devem ser rigorosamente controladas em leite e derivados por indicarem contaminação fecal e causarem séria infecção invasiva em humanos (FRANCO; LANDGRAF, 2003)

Em nenhuma das amostras analisadas em 1999 foi detectada a presença de Salmonella spp. Resultados semelhantes quanto à ausência de Salmonella spp. foram obtidos por Vialta et al. (2002), que analisaram 61 amostras de queijo Minas frescal produzido informalmente na região de Campinas (SP) por Câmara et al. (2002) em estudo realizado com 20 amostras de queijo tipo Minas frescal na cidade de Campo Grande, MS e por Rodrigues et al. (2011), que avaliaram 46 amostras de queijo Minas Frescal em Goiânia (GO). No ano de 2009, uma amostra de queijo Minas (3,33\%), pertencente à marca $A 2$, mostrou-se contaminada com Salmonella spp.

De acordo com o Center for Disease Control and Prevention (CDC) dos EUA, somente em 2011, as DTAs acometeram um em cada seis americanos, sendo responsáveis por 128.000 hospitalizações e 3.000 mortes. As salmonelas não tifoides foram responsáveis por $28 \%$ das mortes por DTAs relatadas em 2011 (CDC, 2012b). No Brasil, Salmonella sp. foi responsável por 869 casos de salmonelose em 2010 (OIE, 2012). Dessa forma, a presença de Salmonella spp. em uma única amostra de queijo é preocupante pelo perigo que este micro-organismo representa para a saúde humana.

Dados publicados também pelo CDC mostraram que as doenças causadas por $S$. aureus representaram 3\% do total de DTAs ocorridas nos EUA em 2011 (CDC, 2012a).

$S$. aureus é um micro-organismo termotolerante e resistente ao sal, podendo permanecer viável em alimentos salgados e cozidos. A importância da presença de $S$. coagulase positiva nos queijos deve-se à capacidade desse micro-organismo em produzir enterotoxina termorresistente causadora de náuseas, vômitos e diarreia em humanos. Contudo, é necessário um grande número de células viáveis de Staphylococcus para que a produção de toxina seja suficiente para oferecer risco a saúde humana (LE LOIR et al., 2003). 
Esse patógeno pode ser encontrado na saliva, mucosa nasal, pele e trato digestivo humano e está presente em elevado número nas feridas purulentas. Também causa infecções na glândula mamária dos bovinos, podendo contaminar o leite. Porém, a adequada pasteurização da matéria-prima para a fabricação de queijo é suficiente para destruir esse micro-organismo. Por isso, a presença de $S$. aureus em queijos produzidos com leite pasteurizado indica condições inadequadas de higiene durante a manipulação e processamento desses produtos (SILVA et al., 2010).

Do total de 55 amostras de queijo Minas, apenas uma amostra $(1,82 \%)$ avaliada em 2009 mostrou contagem acima do limite de $5 \times 102 \mathrm{UFC} / \mathrm{g}$ para S. coagulase positiva (BRASIL, 1996, 2001). Essa amostra apresentou contagem de 3,5 x 104 UFC/g e pertencia à marca E2.

A contaminação por $S$. coagulase positiva encontrada nos queijos Minas frescal avaliados foi menor que a descrita por Loguercio e Aleixo (2001) em amostras comercializadas em Cuiabá (MT) que verificaram contaminação em 96,67\% das amostras. Por sua vez, Carvalho, Viotto e Kuaye (2007) encontraram contagem de $S$. coagulase positiva acima do limite em $12,9 \%$ das amostras de queijo Minas coletadas pelos autores na cidade de Campinas, (SP).

O'Brien et al. (2009) verificaram que $4 \%$ das amostras de queijo frescal artesanal avaliadas na Irlanda mostraram contagem de $S$. coagulase positiva superior a $105 \mathrm{UFC} / \mathrm{g}$. Esses autores consideraram como parâmetro o limite estabelecido pela União Europeia (Commission Regulation (EC) $n$. 2073/2005) para queijos frescais produzidos com leite cru, que deve ser < $105 \mathrm{UFC} / \mathrm{g}$ (EU, 2005). A permissão para a contaminação de queijos por um número maior de células de $S$. coagulase positiva (até 1 x 105 UFC/g) na Europa é justificada pela incapacidade de produção de enterotoxina estafilocócica por populações de Staphylococcus com número de células viáveis inferior a esse valor. Levando-se em conta esse fato, é pouco provável que a amostra de queijo Minas avaliada em 2009, cuja contagem de Staphylococcus foi de 3,5 x 104 UFC/g, apresentasse toxina estafilocócica. Mesmo com número superior a 1 x 105 UFC/g de Staphylococcus em queijos frescos, O'Brien et al. (2009) não detectaram a presença de toxina estafilocócica nas amostras produzidas na Irlanda.
Considerando a contaminação na amostragem representativa de cada marca de queijo (cinco unidades de cada marca), $60 \%$ das marcas de queijo Minas foram consideradas inaceitáveis quanto à contagem de coliformes totais em 1999 e 100\% em 2009. Para a contaminação por $E$. coli, $40 \%$ das marcas analisadas em 1999 e 83,3\% das marcas em 2009 mostraram-se inaceitáveis. Para a presença de Salmonella spp. e contagem de S. coagulase positiva, $100 \%$ das marcas de queijo Minas frescal analisadas em 1999 foram classificadas como satisfatórias. Porém, 16,6\% das marcas em 2009 foram classificadas como inaceitáveis para esses micro-organismos (Figura 1).

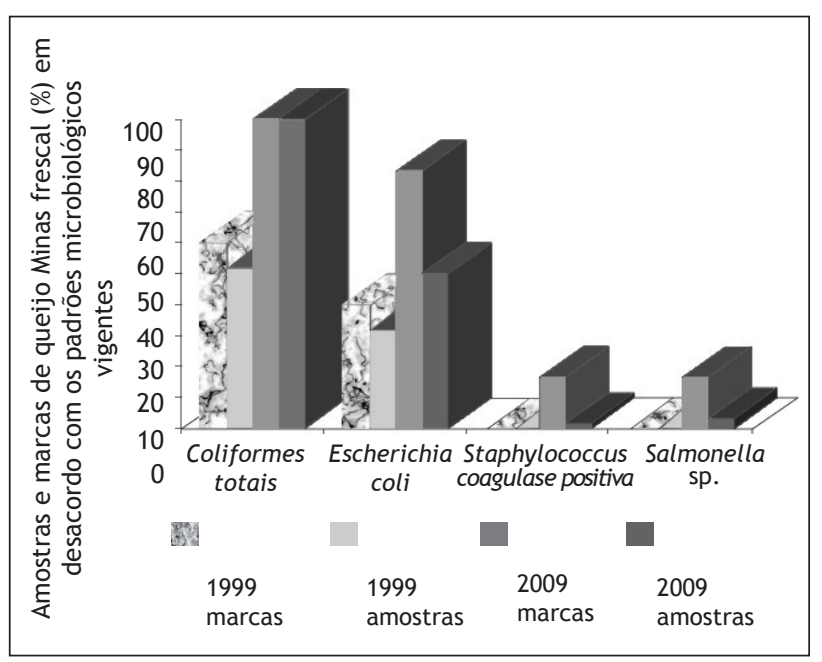

Figura 1 - Frequência de amostras e marcas comerciais de queijo Minas frescal em desacordo com a legislação brasileira (BRASIL, 1996 e 2001) para a contaminação microbiana nos anos de 1999 e 2009 na cidade de Curitiba (PR) Fonte: Dados da pesquisa.

Contrariando a expectativa de aumento do controle higiênico sanitário e de melhoria dos processos tecnológicos de fabricação e armazenamento de queijo Minas frescal em um período de 10 anos, a contaminação das amostras de queijo por microrganismos indicadores, como os coliformes, e patogênicos, como Salmonella spp., S. coagulase positica e E. coli, mostrou-se superior $(\mathrm{p}<0,05)$ nas amostras avaliadas em 2009 em comparação às amostras coletadas em 1999. 
Tendo em vista que $100 \%$ das marcas de queijo avaliadas eram registradas no Serviço de Inspeção Federal ou Estadual, faz-se necessário o controle mais efetivo das diversas fases do processamento de queijo Minas, assim como das condições da matéria-prima, além de programas de incentivo para a implantação de sistemas de garantia da qualidade nas indústrias como as Boas Práticas de Fabricação (BPF), o Programa Padrão de Higiene Operacional (PPHO) e a Análise de Perigos e Pontos Críticos de Controle (HACCP) para garantir a inocuidade do queijo Minas frescal produzido no país.

\section{Conclusão}

Os queijos comercializados e avaliados em 1999 mostraram contaminação microbiana menor que a dos queijos avaliados em 2009, os quais apresentaram pelo menos um dos parâmetros microbiológicos em desacordo com a legislação vigente.

Ainda que os processos tecnológicos de produção de alimentos tenham evoluído, os programas de garantia da qualidade e de boas práticas são os alicerces para a produção de queijos inócuos à saúde do consumidor.

\section{Referências}

ARAÚJO, W. N. et al. Determinação do nível de contaminação por coliformes totais no queijo Minas comercializado na região metropolitana de Salvador - Bahia. Revista Brasileira de Saúde e Produção Animal, v. 2, n. 1, p. 5-9, 2001.

BEHMER, M. L. A. Tecnologia do leite: leite, manteiga, queijo, caseína, sorvetes e instalações: produção, industrialização, análise. 13 ed. rev. atual. São Paulo: Nobel, 1999.

BRASIL. Ministério da Agricultura do Abastecimento e da Reforma Agrária. Secretaria de Defesa Agropecuária. Departamento de Defesa Animal. Manual de Métodos Microbiológicos para Alimentos, 1992.

BRASIL. Ministério da Agricultura, do Abastecimento e da Reforma Agrária. Portaria n. 146 de 07 de março de 1996. Aprova o Regulamento Técnico de Identidade e Qualidade de Queijos. Diário Oficial [da] União, Brasília, 11 mar. 1996.
BRASIL. Ministério da Agricultura e do Abastecimento. Portaria n. 352, de 4 de setembro de 1997. Aprova o Regulamento Técnico para Fixação e Qualidade de Queijo Minas Frescal. Diário Oficial [da] União, Brasília, 8 set. 1997.

BRASIL. Ministério da Saúde. Agência Nacional de Vigilância Sanitária (Anvisa) - RDC n. 12 de 2 de janeiro de 2001. Regulamento Técnico sobre Padrões Microbiológicos para Alimentos. Diário Oficial [da] União. Brasília, 10 jan. 2001, Anexo I, grupo 8a.

BRASIL. Ministério da Agricultura, Pecuária e do Abastecimento. Secretaria de Defesa Agropecuária. Instrução Normativa n. 62 de 26 de agosto de 2003. Oficializa os Métodos Analíticos Oficiais para Análises Microbiológicas para Controle de Produtos de Origem Animal e Água. Diário Oficial [da] União, Brasília, 18 set. 2003.

BRASIL. Ministério da Agricultura, Pecuária e do Abasteci mento. Instrução Normativa n. 4 de 1 de março de 2004. Inclusão do termo "Muito" na definição do queijo Minas frescal no Regulamento Técnico para fixação de Identidade e Qualidade do Queijo Minas Frescal, Diário Oficial [da] União, Brasília, 5 mar. 2004.

BRASIL. Ministério da Agricultura, Pecuária e do Abastecimento. Instrução Normativa n. 62 de 29 de dezembro de 2011. Aprova o Regulamento Técnico de Produção, Identidade e Qualidade do Leite tipo A, o Regulamento Técnico de Identidade e Qualidade de Leite Cru Refrigerado, o Regulamento Técnico de Identidade e Qualidade de Leite Pasteurizado e o Regulamento Técnico da Coleta de Leite Cru Refrigerado e seu Transporte a Granel. Diário Oficial [da] União, Brasília, 30 dez. 2011.

CÂMARA, S. A. V.; AMARAL, G. B.; MULLER, M. T. Avaliação microbiológica de queijos tipo minas frescal artesanal, comercializados no mercado municipal de Campo Grande, Mato Grosso do Sul, 2000. Higiene Alimentar, v. 16, n. 101, p 32-36, 2002.

CENTERS FOR DISEASE CONTROL AND PREVENTION - CDC. Staphylococcal Food Poisoning. 2012a. Disponível em: <http:www.cdc.gov/ncidod/dbmd/diseaseinfo/staphylococcus_food_g.htm\#2>. Acesso em: 26 mar. 2012.

CENTERS FOR DISEASE CONTROL AND PREVENTION CDC. CDC Estimates of Foodborne Illness in the United States. 2012b. Disponível em: <http://www.cdc.gov/foodborneburden/2011-foodborne-estimates.html>.Acesso em: 26mar.2012. 
CARVALHO, J. D. G.; VIOTTO, W. H.; KUAYE, A. Y. The quality of Minas Frescal cheese produced by different technological processes. Food Control, v. 18, p. 262-267, 2007.

EUROPEAN UNION. Commission Regulation (EC) $\mathrm{n}$. $2073 / 2005$ on microbiological criteria for foodstuffs. Official Journal of the EU, n. 338, p. 1-26, 2005.

DE BUYSER, M. L. et al. Implication of milk and milk products in food-borne diseases in France and different industrialized countries. International Journal of Food Microbiology, v. 67, n. 1-2, p. 1-17, 2001.

EMPRESA BRASILEIRA DE PESQUISA AGROPECUÁRIA EMBRAPA. . Estatísticas do Leite. Disponível em:<http:// www.cnpgl.embrapa.br>. Acesso em: 23 abr. 2010.

FEITOSA, T. et al. Pesquisa de Salmonella sp, Listeria sp e microrganismos indicadores higiênico-sanitários em queijos produzidos no Estado do Rio Grande do Norte. Ciência e Tecnologia de Alimentos, v. 23, p. 162-165, 2003.

FRANCO, B. D. G. M.; LANDGRAF, M. Microbiologia dos alimentos. São Paulo: Editora Atheneu, 2003.

FRANK, J. F; CHRISTEN, G. L.; BULLERMAN, L. B. Tests for groups of microorganisms. In: MARSHALL, R. T. Standard methods for the examination of dairy products. Washington: American Public Health Association, 2005. p. 271-286.

FURTADO, M. M.; LOURENÇO NETO, J. P. M. Tecnologia de queijos. Manual técnico para produção industrial de queijos. São Paulo: Dipemar, 1994.

FURTADO, M. M. Principais problemas dos queijos: causas e prevenção. São Paulo: Fonte, 1999.

INMETRO. Leite tipo B, Tipo C, UHT e Queijo Minas Frescal e Prato. 1999. Disponível em < www.inmetro.gov. br>. Acesso em: 13 de jun. 2009.

ISEPON, J. S.; SANTOS, P. A.; SILVA, M. A. P. Avaliação microbiológica de queijos Minas frescal comercializados na cidade de Ilha Solteira - SP. Higiene Alimentar, v. 17, n. 106, p. 89-94, 2003.

LEITE, R. L. et al. Estudo das condições higiênico-sanitárias de queijos "Minas Frescal" e "Minas Padrão" elaborados a partir de leite proveniente de vacas com mastite subclínica. Revista do Instituto de Laticínios Cândido Tostes, v. 56, n. 320, p. 03-11, 2001.

LE LOIR, Y., BARON, F., GAUTIER, M. Staphylococcus aureus and food poisoning. Genetic Molecular Research, v. 2, n. 1, p. 63-76, 2003.
LOGUERCIO, A. P.; ALEIXO, J. A. G. Microbiologia de queijo tipo Minas frescal produzido artesanalmente. Revista Ciência Rural, v. 31, n. 6, 2001.

MOSSEL, D. A. A.; MORENO, G. B. Microbiologia dos alimentos: fundamentos ecológicos para garantizar y comproblar la inocuidade y calidade de los alimentos. Zaragoza: Acribia, p. 375, 1988.

O'BRIEN, M. et al. Occurrence of foodborne pathogens in Irish farmhouse cheese. Food Microbiology, v. 26, n. 8, p. 910-914, 2009.

PEREIRA, C. I.; GOMES, A. M. P.; MALCATA, F. X. Microstructure Cheese: Processing technological and microbiological considerations. Trends in Food Science \& Technology, v. 20, p. 213-19, 2009.

PEREIRA, M. L. et al. Intoxicação por Staphylococcus aureus provocada por queijo "tipo Minas". Revista de Microbiologia, v. 22, p. 349-350, 1991.

PERRY, K. S. P. Queijos: aspectos químicos, bioquímicos e microbiológicos. Química Nova, v. 27, n. 2, p. 293-300, 2004.

RODRIGUES, J. et al. Levantamento das características físico-químicas e microbiológicas de queijo Minas frescal e mussarela produzido no entorno de Goiânia - GO. Revista da Universidade Vale do Rio Verde, v. 9, Supl. 1, p. 30-34, 2011.

RUDOL, M., SCHERER, S. High incidence of Listeria monocytogenes in European red smear cheese. International Journal of Food Microbiology, v. 63, p. 91-98, 2001.

SÃO PAULO. Secretaria de Saúde. Código Sanitário. Decreto n. 12.342, de 27 de setembro de 1978. Regulamento da Promoção, Preservação e Recuperação da Saúde no Campo da Competência da Secretaria de Estado da Saúde. 5. ed. (Revisto e atualizado até dezembro de 1990). São Paulo: IMESP, 1992.

SALOTTI, B. M. et al. Qualidade microbiológica do queijo Minas frescal comercializado no município de Jaboticabal, SP - Brasil. Arquivo do Instituto de Biologia, v. 73, n. 2, p. 171-175, 2006.

SEBRAE. Queijos nacionais. Estudo de mercado Sebrae/ ESPM. Série mercado. São Paulo: Serviço Brasileiro de Apoio às Micro e Pequenas Empresas, 2008, 34 p.

SILVA, N. et al. Manual de métodos de análise microbiológica de alimentos e água. 3 ed. São Paulo: Varela, 2007. 
SILVA, N. et al. Manual de métodos de análise microbiológica de alimentos e água. 4 ed. São Paulo: Varela, 2010.

SIQUEIRA, R. S. Manual de microbiologia de alimentos. Rio de Janeiro: EMBRAPA, 1995.

SOUZA, T. B. et al. Microscopic quality indicators of Minas frescal cheese. Food Control, v. 19, p. 71-75, 2008.

VIALTA, A.; MORENO, I.; LERAYER, A. L. S. Caracterização microbiológica e microscópica de queijo Minas produzido informalmente. In: XVIII CONGRESSO BRASILEIRO DE CIÊNCIA E TECNOLOGIA DE ALIMENTOS. Anais... Porto Alegre, 2002.

WORLD ORGANIZATION FOR ANIMAL HEALTH - OIE. Zoonoses in Humans. Disponível em: <http://web.oie. int/wahis/public.php>. Acesso em: 26 mar. 2012.

WORLD HEALTH ORGANIZATION - WHO. Foodborne diseases. 2012a. Disponível em: <http://www.who.int/topics/foodborne_diseases/en/>. Acesso em: 26 mar. 2012.
WORLD HEALTH ORGANIZATION - WHO. Regional Office for Europe. Outbreaks of E. coli 0104:H4 infection: update 30. 2012b. Disponível em: <http://www.euro. who.int/em/what-we-do/health-topics/emergencies/ international-healthregulations/news/news/2011/07/ outbreaks-of-e.-coli-o104h4-infection-update-30>. Acesso em: 26 mar. 2012.

WOLFSCHOON-POMBO, A. L. Índice de proteólise em alguns queijos brasileiros. Boletim do Leite e seus Derivados, v. 56, n. 61, p. 1-8, 1983.
Recebido: 16/04/2012 Received: 04/16/2012

Aprovado: 29/10/2012 Approved: 10/29/2012 